stehen. Jetzt fügt man $1 \mathrm{ccm}$ Amylalkohol hinzu, füllt dann mit Schwefelsäure bis zum Teilstrich 35 auf und durchmischt den Butyrometer-Inhalt ohne zu schütteln vorsichtig ${ }^{1}$ ), nur so lange schwenkend, als für eine gute Durchmischung notwendig ist. Nun läß̊t man etwa 5 Minuten ruhig im Wasserbade bei $65^{\circ} \mathrm{C}$. stehen und zentrifugiert dann 4. Minuten lang mit 1000 Umdrehungen in der Minute (bei niedriger Zimmertemperatur in einer erwärmten Zentrifuge).

Hierauf stellt man das Butyrometer weitere 5 Minuten in das Wasserbad von $65^{\circ}$ C. und liest das Frgebnis auch bei $65^{\circ}$ ab. - Die flachen Butyrometer gestatten besonders eine sehr scharfe Ablesung.

Auch für die Untersuchung von nicht zu fettem Rahm sind diese englumigen Butyrometer sehr gut verwendbar.

Diese modifizierten Käse-Butyrometer, nach meinen Angaben angefertigt, können durch Dr. N. Gerber's Co. in Leipzig und deren Agenturen bezogen werden.

1) Vgl. J. van Haarst in Zeitschr. angew. Chem. 1903, 16, 451-453 u. 773-776; Siegfeld in Milch-Ztg. 1904, 38, 289, Alb. Scala in dieser Zeitschift 1906, 11, 410; Besse in Milch-Ztg. 1907, 36, 352.

\title{
Bestimmung der Rohfaser bei staubartig feinen Stoffen.
}

Von

\section{W. Greifenhagen.}

Mitteilung aus dem Chemischen Untersuchungsamteder Stadt Harburga. E. (Eingegangen am 3. Januar 1912.)

Die Bestimmung der Rohfaser bei Baumwollsaatmehl, Kakao und dergl. staubartig feinen Stoffen unterliegt bekanntlich nach dem Verfahren von J. König einigen Schwierigkeiten. Man soll die gekochte oder gedämpfte Flüssigkeit in großen Bechergläsern stärker verdünnen, sich absetzen lassen, die völlig klare Flüssigkeit einmal abhebern und dann den Bodensatz nach dem Verdünnen und Kochen filtrieren. Diese Filtration ist aber durchaus nicht einfach und beansprucht ziemlich viel Zeit. Es gibt nun ein einfaches Verfahren, um auch für solche schwer filtrierbaren Stoffe das J. König'sche Verfahren in Anwendung bringen zu können. Man verwendet eine Nutsche von $10,5 \mathrm{~cm}$ Durchmesser; sollte diese nicht vorhanden sein, so kann man sich wohl einer etwa gleich großen Porzellanplatte bedienen, die man in einen Trichter einlegt. Auf diese breitet man eine nicht allzu dicke, aber doch genügend starke Asbestlage aus und saugt kräftig an. Darauf filtriert man die unverdünnte, heiße Flüssigkeit ohne weiteres durch. Die Nutsche, welche ich für diese Zwecke benutzte, war $3,5 \mathrm{~cm}$ hoch, sodaß ohne weiteres sämtliche $200 \mathrm{ccm}$ auf einmal aufgegossen werden konnten; ebensogut kann man aber auch die Flüssigkeit portionsweise darauf bringen. Die Filtration und das Auswaschen läßt nichts zu wünschen 
übrig und ist in wenigen Minuten beendigt. In einer Zeit, wo wir in dem hiesigen Amt reichlich mit Kakaoproben versehen wurden, filtrierte ich in 2 Stunden 8 Rohfaserbestimmungen einschlieflich Auswaschen and Trocknen. Nach dem früheren Verfahren wäre dies wohl nicht möglich gewesen.

2 Doppelbestimmungen, welche ich gemeinsam mit Herrn Dr. Bremer, dem Vorsteher des hiesigen Untersuchungsamtes, ausführte, will ich hier angeben:

$$
\text { Kakao . . . . . 13,80; 13,83\% Rohfaser }
$$

Baumwollsaatmehl 7,$77 ; 7,63 \%$,

Wegen der Einfachheit des Verfahrens führe ich jetzt sämtliche Rohfaserbestimmungen auf diese Weise aus und habe bis jetzt irgend welche Schwierigkeiten nicht beobachten können.

Erwähnenswert erscheint mir noch der Autoklaveneinsatz von W. Bremer ${ }^{\mathbf{1}}$ ); er besteht im Gegensatz zu dem früher gebräuchlichen aus Porzellanbechern, welche mancherlei Vorteile bieten. Ganz abgesehen davon, daß man bei ihrer Benutzung 8 statt 4 Proben gleichzeitig aufschließen kann, eignen sie sich auch bedeutend besser zur Filtration als Schalen. Einen weiteren Vorteil ersehe ich auch darin, daß man in den Bechern bei dem tiefliegenden Boden Alkohol und Äther gut erwärmen kann. Kommen diese einmal zum Brennen, so genügt ein Bedecken mit dem Deckel, um den Brand zu ersticken. Ein Zerbrechen des Bechers durch die entstandene Hitze ist ausgeschlossen. Bei Bechergläsern dagegen ist ein derartiges Verfahren immer eine gewagte Sache.

1) Diese Zeitschrift 1907, 13, 488.

\section{Berichtigung.}

In der in Heft 1 des laufenden Bandes dieser Zeitscbrift veröffentlichten Arbeit:

\section{Sind Alkalität und ,Peroxydase" der Milch identische Begriffe? \\ Von W. D. Kooper.}

ist bei der Korrektur leider ein Verseben unterlaufen, das hiermit berichtigt sei.

Die erste Zeile dieser Arbeit muB lauten:

„Die vor kurzem von Hesse und Verfasser in dieser Zeitschrift (1911, 21, 393) ausgesprochene Vermutung, ...."

Redaktion.

\section{Referate.}

\section{Mikroskopische und bakteriologische Untersuchungsmethoden.}

A. Wolff-Eisner: Ein neuer leistungsfähiger Schüttelapparat in Verbindung mit einem Thermostaten. (Zentralbl. Bakteriol. I. Abt., Orig., 1909, 49, 654--656.) - Der Apparat bewirkt gleichzeitig Bewegungen in seitlicher als auch in senkrechter Richtung. Er kann durch einen 1/8-pferdigen Motor oder durch eine Turbine angetrieben werden. Für Ausschüttelungen bei bestimmten Temperaturen 